\title{
Evaluation of skills of intensive care nurses regarding central venous catheter care: An observational study
}

\author{
Gulnur KAR ${ }^{1}$ (D), Ebru EREK KAZAN² (D) \\ ${ }^{1}$ General Intensive Care Unit, Istanbul Beykoz State Hospital, Istanbul, Turkey. \\ ${ }^{2}$ Department of Nursing, Faculty of Health Sciences, Ankara Yildirim Beyazit University, Ankara, Turkey.
}

Corresponding Author: Ebru EREK KAZAN

E-mail: eekazan@ybu.edu.tr

Submitted: 27.03.2021 Accepted: 01.05.2021

\begin{abstract}
Objective: Central venous access is a common procedure performed in many clinical settings for a variety of indications. Yet, there are multiple complications related to central venous catheter use. Significant morbidity and mortality can result from complications related to central venous catheters. Therefore, safety and effectiveness of central venous catheter care by nurses is crucial. The aim of this study was to evaluate the intensive care nursing skills associated with central venous catheter care.

Materials and Methods: This observational study was conducted with 37 volunteer nurses who were employed in adult intensive care units of three hospitals in Istanbul, Turkey. A total of 111 observations were collected by using the Nurses' Descriptive Characteristics Form and the Intensive Care Nurses' Central Venous Catheter Care Skills Observation Checklist.

Results: The average age of the nurses was $33.2 \pm 5.9$ years. The study showed that $93.7 \%$ nurses had performed the hand hygiene before starting the central venous catheter care but seldom after the procedure. Sterile gloves were not used by majority of the nurses during the care. They almost never disinfected the catheter hub, and they did not adequately obey the rules after completing the care procedure.

Conclusions: This study demonstrated that nurses had inadequate skills of central venous catheter care. We recommend that nurses' skills must be enriched with professional theoretical and practical trainings.

Keywords: Central venous catheter, Intensive care, Nurse, Nursing care, Skill.
\end{abstract}

\section{INTRODUCTION}

Central venous catheters (CVCs) are invasive tools utilized, especially in intensive care units (ICUs), for infusion treatments, nutritional support, hemodynamic monitoring, blood and blood product transfusion, and hemodialysis. CVCs have significant advantages for medical treatment, but they can also cause various serious complications [1]. Side effects associated with long-term CVC use include catheter-related bloodstream infection (CRBSI), bleeding, and thrombosis [2].

Central venous catheters are reported to cause 250,000 cases of CRBSI every year in the United States alone, and of these infections, 67,500 result in death [3]. A Turkish study that investigated healthcare-related infections in ICUs indicated that CRBSI was the most common type of infection, making up $48 \%$ of all cases, and had a mortality rate of $63.3 \%$ [4]. These CRBSIs not only negatively impact patients' medical conditions but are also known to increase the length of hospital stay and increase workload and costs. With all this in mind, it is extremely important to prevent infections before they occur. Proper nursing care can prevent the development of both infections and other catheter-related complications [5]. CVCs are most commonly used in intensive care settings. The intensive care nurse should be able to follow the patient's overall condition, know the catheter selection and the purpose of closing the catheter site, be able to follow the best techniques

\footnotetext{
* This study was produced from master thesis. The study, was presented as an oral presentation on December 19-21, 2019 at the 6th International 17th National Nursing Congress organized by Gazi University in Ankara/ Turkey.
}

How to cite this article: Kar G, Kazan Erek E. Evaluation of intensive care nurses' skills associated with care of central venous catheter: An observational study. Marmara Med J 2021; 34(3):298-306. doi: 10.5472/marumj.1012090 
during catheter insertion, correctly practice catheter care, and properly manage the catheter to avoid infections [6]. Therefore, proper CVC management requires both sufficient theoretical knowledge and practical experience.

Most studies that investigated knowledge of nurses on CVC care indicated that they had inadequate knowledge [7-13] and that this knowledge could be improved by training $[10,11]$ and experience $[12,13]$. Inadequate knowledge also negatively affects nurses' practical skills, since, nursing is an applied health discipline that requires a combination of theoretical content with practical skills $[14,15]$. However, there are a limited number of studies that evaluate nurses' CVC care skills [11,16-18] and none that directly investigate the CVC care skills of nurses. The most accurate way to evaluate the compliance of nurses with guidelines is to observe nurses directly during daily work routines and to examine their practices $[19,20]$. Therefore, this study was planned to evaluate the CVC care skills of ICU nurses via an observational technique.

This study aims to evaluate the intensive care nurses' skills associated with CVC care.

\section{MATERIALS and METHODS}

\section{Design and sample}

The research was conducted with nurses employed in adult ICUs of one public hospital, one university hospital, and one private hospital in Istanbul, Turkey, using the non-participant structured observation technique.

The research population consisted of 156 nurses working in the adult ICUs of the three hospitals as of May 2019. Ten nurses working in the general ICU of the public hospital (i.e., the workplace of the researcher) and 16 nurses who could not be reached due to being on a leave of absence were excluded from the study. In addition, due to the lack of patients on CVCs, 29 nurses working in 3 ICUs of the public hospital were also excluded. Therefore, the size of the research population was determined as $\mathrm{n}=101$.

There was no sampling. Instead, the sample was made up of 37 nurses who volunteered to participate in the study $(n=37)$. In all three hospitals, the nurses worked in shifts, and the clinics employed CVC care procedures.

\section{Measurement and instruments}

During the research duration, each nurse was observed 3 times while performing CVC care. The accuracy of how a nurse behaves cannot be determined with one observation, and when two observations are made, it is uncertain which of the two different behaviors more accurately reflects actuality. For this reason, as per the expert opinion of a statistician, we decided to make 3 observations for each nurse to ensure the reliability of the results. Our review of the literature revealed that other observational studies similarly used at least 3 observations $[21,22]$.
We used two data collection tools in the study. These were the Nurses' Descriptive Characteristics Survey Form (Form 1) and the Intensive Care Nurses' Central Venous Catheter Care Skills Observation Form (Form 2).

\section{Form 1: Nurses' Descriptive Characteristics Survey Form}

This 12 item form was prepared by the researchers as per the literature $[8,22,23]$. The form consists of 5 items that investigate the sociodemographic characteristics of the nurses and 7 items concerning training and available resources related to CVC care.

\section{Form 2: Intensive Care Nurses' Central Venous Catheter Care Skills Observation Checklist}

This checklist was prepared by the researchers to determine the ICU nurses' CVC care-related skills as per the relevant literature [24-28]. The checklist consists of the CVC care procedure divided into 41 steps. It was designed so that each step is marked as "performed" or "not performed", and the results of all three observations can be recorded on the same checklist. Six experts were consulted to evaluate the content validity of the data collection tools. The results of this evaluation indicated that all items of both forms were sufficient for content validity (content validity index $(\mathrm{CVI})>0.80)$.

\section{Data collection}

First, a pilot study was conducted among nurses working in ICUs of a separate hospital to test the research tools for usability. The study then moved on to the application phase. The study was conducted in the adult ICUs of three hospitals in May 2019. The nurses were provided with an explanation of the study by the researcher and were informed that they would be observed 3 times while providing CVC care. The nurses agreeing to participate in the study signed informed consent forms and filled out Form 1. The study then moved on to the observational stage. If a sufficient number of patients with CVC were available on the day that Form 1 was filled out, the nurses were observed on the same day. If the number was insufficient, each nurse was asked to make an appointment to avoid affecting their routine work, and each nurse was observed three times at different times. Nurses were evaluated using the non-participant structured observational design. Each observation lasted approximately 20 minutes. The nurses were not provided with feedback until, after all three observations were completed in order to avoid affecting their behavior. A total of 111 observations were made.

The study was granted ethical approval by the Ethics Committee of Ankara Yildirim Beyazit University in Ankara, Turkey (Date: 21/11/2018, Number: 102). Written permission was obtained from the administrations of all hospitals. After being informed about the research, all nurses who agreed to participate in the study signed informed consent forms.

\section{Statistical analysis}

Data were analyzed using IBM SPSS Statistics software version 25.0. When nurses performed a step indicated in the CVC assessment form two or three times out of three observations, 
they were considered to have "performed" the step. When nurses performed a step indicated in the CVC assessment form once out of three observations or did not perform it at all, they were considered to have "not performed" the step. The observation results of each step of the CVC procedure are presented as numbers and percentages in Table I.

The demographic characteristics of the nurses are presented as numbers and percentages. The nurses' demographic data were compared with the CVC care process steps. To facilitate the presentation of data, we only included the results of the critical steps of the CVC care process (25 steps), as elaborated in the literature [24-28]. The Z-test was used to determine the correlation of the observation results for two-category variables, and the chi-square test was used to determine the correlation of the observation results with variables with three or more categories (e.g., age, educational status). Fisher's exact test was used for pair wise comparisons. A p-value of less than 0.05 ( $p<$ $.05)$ was considered statistically significant.

\section{RESULTS}

The average age of the nurses included in the study was 33.2 \pm 5.9 years (range: $21-41$ ), and most (86.5\%) were women. Furthermore, $67.6 \%$ of the nurses had undergraduate degrees. Other demographic data are presented in Table I.

Table 1. Demographic characteristics of the nurses $(n=37)$

\begin{tabular}{|l|c|c|}
\hline Demographic characteristics & n & $\%$ \\
\hline Age & 11 & 29.8 \\
\hline$\leq 25$ & 16 & 43.2 \\
$26-29$ & 10 & 27.0 \\
$\geq 30$ & 32 & 86.5 \\
\hline $\bar{X} \pm S D=33.2 \pm 5.9$ min=21 age max=41 age & 13.5 \\
\hline Gender & 5 & 16.2 \\
\hline Female & 6 & 67.6 \\
Male & 25 & 16.2 \\
\hline Educational status & 6 & 54.0 \\
\hline Nursing vocational high school & 20 & 46.0 \\
\hline Bachelor's degrees & 17 & \\
Master's degrees & 17 & 46.0 \\
\hline Nursing Experience & 20 & 54.0 \\
\hline$<5$ years \\
$\geq 5$ years \\
\hline $\bar{X} \pm S D=5.9 \pm 4.6$ min= 8 months max $=21$ years \\
\hline Experience in ICU \\
\hline$<5$ years \\
$\geq 5$ years \\
\hline $\bar{X} \pm S D=5.9 \pm 3.2$ min= 3 months max $=13$ years \\
\hline
\end{tabular}

It was found that $75.7 \%$ of nurses stated that they had received training on CVC care; most (89.3\%) stated that they primarily received "in-service" training, and $85.7 \%$ stated that the provided training was "adequate". Only $32.4 \%$ of the nurses stated that they had utilized resources on CVC care. Other data concerning training and available resources related to CVC care are presented in Table II.

Table II. Distribution of the nurses' CVC care characteristics ( $n=37$ )

Characteristics regarding $\mathrm{CVC}$ care training and resources n $\%$ CVC training status

Received training

Did not receive training

Type of training $(\mathrm{n}=28)^{\star}$

In-service training

Basic vocational training

Conference/convention

Course

Internet

Seminar

Form of training $(\mathrm{n}=28)$

Only theoretical

Only practical

Both theoretical and practical

\begin{tabular}{|l|l|}
\hline 28 & 75.7 \\
9 & 24.3 \\
\hline
\end{tabular}

Adequacy of training $(\mathrm{n}=28)$

\begin{tabular}{|l|l|l|}
\hline Adequate & 24 & 85.7 \\
Partly adequate & 4 & 14.3 \\
\hline
\end{tabular}

Resource availability in the workplace

Available

Not available

\begin{tabular}{|l|l|}
\hline 12 & 32.4 \\
25 & 67.6 \\
\hline
\end{tabular}

Type of resource referred to $(n=12)$

Hospital information system

Nursing textbooks

Internet

Frequency of CVC care application *

Per shift (n=14)

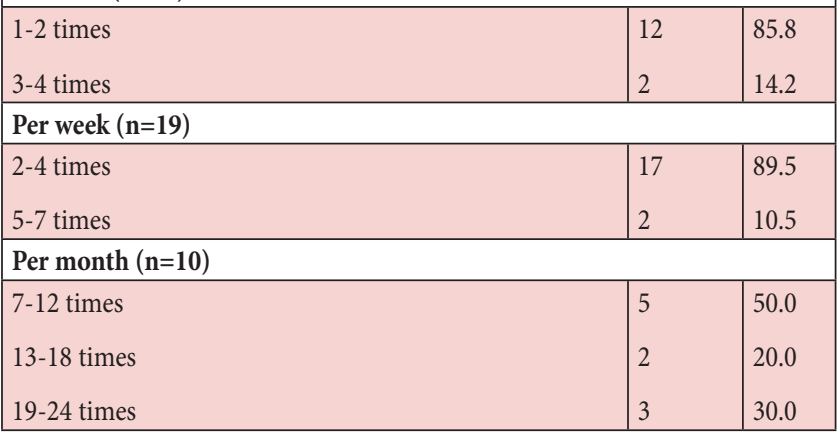

${ }^{*} n$ has increased due to multiple responses

Table III presents the results of a total of 111 observations of 37 nurses that were made to determine their skills in the 
critical steps of the CVC care process (25 steps). We compared the observational results with the nurses' demographic characteristics, and we specify our findings in the text.

Ninty-three point seven percent in all three observation stages, nurses performed hand hygiene before starting the care process, while, only $24.3 \%$ used masks (Table III). The mask use rate was significantly higher in the group that did not receive training on CVC care than among those who did $(\mathrm{p}=.015)$.

We noted that after touching soiled dressings, few nurses removed their gloves ( $49.5 \%$ of all the three observations), performed hand hygiene ( $16.2 \%$ of all the three observations) and used sterile gloves (29.7\% of all the three observations). None of the nurses aged $\leq 25$ years wore sterile gloves for catheter dressing, while the nurses aged 26-29 years and those aged $\geq 30$ years used sterile gloves significantly more than those aged $\leq 25$ years (respectively $\mathrm{p}=.022 ; \mathrm{p}=.035 ; \mathrm{p}<.05$ ). In addition, nurses who had graduated from nursing vocational high schools never wore sterile gloves, while nurses with master's degrees did so significantly more than nurses with vocational high school and bachelor's degrees (respectively $\mathrm{p}=.030 ; \mathrm{p}=.043 ; \mathrm{p}<.05$ ).
Nurses waited for the region wiped with an antiseptic solution to air-dry in $72.1 \%$ of the observations (Table III). Only $10.8 \%$ of the nurses wiped the catheter hub with an antiseptic solution, and nurses with more than 5 years of ICU experience were found to do so significantly more often $(\mathrm{p}=.004)$. Additionally, nurses aged $\geq 30$ years were found to perform this step significantly more often than nurses aged $\leq 25$ years $(\mathrm{p}=.035 ; \mathrm{p}<.05)$.

In our study, none of the nurses performed the step in which the syringe was withdrawn to observe positive blood return in any of the 111 observations (Table III). Only 5.4\% of all nurses flushed the catheter hub with sodium chloride solution, and $25.2 \%$ placed a new cap on the hub (Table III).

Nurses performed hand hygiene after removing their gloves, after providing care only $40.5 \%$ of the time, and this rate was significantly higher in the group aged $\leq 25$ years than in those aged $26-29$ years $(\mathrm{p}=.015 ; \mathrm{p}<.05)$. Other observation assessment findings are presented in Table III.

Table III. Observation results of critical steps of $C V C$ care process

\begin{tabular}{|c|c|c|c|c|c|c|c|c|c|c|c|c|c|c|c|c|}
\hline \multirow{4}{*}{$\begin{array}{l}\text { Critical steps of the CVC } \\
\text { care process }\end{array}$} & \multicolumn{16}{|c|}{ CVC Care Observation Results } \\
\hline & \multicolumn{4}{|c|}{ 1. Observation $(\mathrm{n}=37)$} & \multicolumn{4}{|c|}{ 2. Observation $(\mathrm{n}=37)$} & \multicolumn{4}{|c|}{ 3. Observation $(n=37)$} & \multicolumn{4}{|c|}{ Total $(n=111)$} \\
\hline & \multicolumn{2}{|c|}{ Performed } & \multicolumn{2}{|c|}{ Not Performed } & \multicolumn{2}{|c|}{ Performed } & \multicolumn{2}{|c|}{$\begin{array}{c}\text { Not } \\
\text { Performed } \\
\end{array}$} & \multicolumn{2}{|c|}{ Performed } & \multicolumn{2}{|c|}{$\begin{array}{c}\text { Not } \\
\text { Performed }\end{array}$} & \multicolumn{2}{|c|}{ Performed } & \multicolumn{2}{|c|}{$\begin{array}{c}\text { Not } \\
\text { Performed } \\
\end{array}$} \\
\hline & $\mathrm{n}$ & $\%$ & $\mathrm{n}$ & $\%$ & $\mathrm{n}$ & $\%$ & $\overline{\mathrm{n}}$ & $\%$ & $\mathrm{n}$ & $\%$ & $\mathrm{n}$ & $\%$ & $\mathrm{n}$ & $\%$ & $\mathrm{n}$ & $\%$ \\
\hline 1. Hand hygiene is performed. & 35 & 94.6 & 2 & 5.4 & 35 & 94.6 & 2 & 5.4 & 34 & 91.9 & 3 & 8.1 & 104 & 93.7 & 7 & 6.3 \\
\hline $\begin{array}{l}\text { 2. The required equipment is } \\
\text { prepared; } \\
\text { a) Masks ( } 1 \text { each for the } \\
\text { patient and the nurse) }\end{array}$ & 9 & 24.3 & 28 & 75.7 & 9 & 24.3 & 28 & 75.7 & 9 & 24.3 & 28 & 75.7 & 27 & 24.3 & 84 & 75.7 \\
\hline b) Sterile gloves & 11 & 29.7 & 26 & 70.3 & 11 & 29.7 & 26 & 70.3 & 11 & 29.7 & 26 & 70.3 & 33 & 29.7 & 78 & 70.3 \\
\hline c) Sterile gauze & 37 & 100.0 & - & - & 37 & 100.0 & - & - & 37 & 100.0 & - & - & 111 & 100.0 & - & - \\
\hline $\begin{array}{l}\text { d) An antiseptic solution in } \\
\text { accordance with institutional } \\
\text { policy for catheter entrance } \\
\text { site care }\end{array}$ & 37 & 100.0 & - & - & 37 & 100.0 & - & - & 37 & 100.0 & - & - & 111 & 100.0 & - & - \\
\hline $\begin{array}{l}\text { e) Sterile transparent or gauze } \\
\text { dressing }\end{array}$ & 37 & 100.0 & - & - & 37 & 100.0 & - & - & 37 & 100.0 & - & - & 111 & 100.0 & - & - \\
\hline $\begin{array}{l}\text { f) } 2 \% \text { chlorhexidine } \\
\text { gluconate, povidone iodine or } \\
\text { alcoholic wipes for cleaning } \\
\text { the catheter hub }\end{array}$ & 6 & 16.2 & 31 & 83.8 & 6 & 16.2 & 31 & 83.8 & 6 & 16.2 & 31 & 83.8 & 18 & 16.2 & 93 & 83.8 \\
\hline $\begin{array}{l}\text { g) } 10 \mathrm{~mL} \text { syringes (as per the } \\
\text { number of lumens) }\end{array}$ & 2 & 5.4 & 35 & 94.6 & 2 & 5.4 & 35 & 94.6 & 2 & 5.4 & 35 & 94.6 & 6 & 5.4 & 105 & 94.6 \\
\hline $\begin{array}{l}\text { h) } 0.9 \% \text { sodium chloride } \\
\text { solution }\end{array}$ & 2 & 5.4 & 35 & 94.6 & 2 & 5.4 & 35 & 94.6 & 2 & 5.4 & 35 & 94.6 & 6 & 5.4 & 105 & 94.6 \\
\hline $\begin{array}{l}\text { i) Positive pressure end } \\
\text { caps (as per the number of } \\
\text { lumens) }\end{array}$ & 11 & 29.7 & 26 & 70.3 & 10 & 27.0 & 27 & 73.0 & 10 & 27.0 & 27 & 73.0 & 31 & 27.9 & 80 & 72.1 \\
\hline
\end{tabular}




\begin{tabular}{|c|c|c|c|c|c|c|c|c|c|c|c|c|c|c|c|c|}
\hline $\begin{array}{l}\text { 3. The procedure is explained to } \\
\text { the patient, provided that they } \\
\text { are conscious. }\end{array}$ & 18 & 48.6 & 19 & 51.4 & 13 & 35.1 & 24 & 64.9 & 11 & 29.7 & 26 & 70.3 & 42 & 37.8 & 69 & 62.2 \\
\hline 4. The mask is put on. & 9 & 24.3 & 28 & 75.7 & 9 & 24.3 & 28 & 75.7 & 9 & 24.3 & 28 & 75.7 & 27 & 24.3 & 84 & 75.7 \\
\hline $\begin{array}{l}\text { 5. The patient's head is turned } \\
\text { in the opposite direction of the } \\
\text { catheter, and if it cannot be } \\
\text { turned, a mask is put on his/ } \\
\text { her face. }\end{array}$ & 5 & 13.5 & 32 & 86.5 & 4 & 10.8 & 33 & 89.2 & 4 & 10.8 & 33 & 89.2 & 13 & 11.7 & 98 & 88.3 \\
\hline 6. Disposable gloves are put on. & 36 & 97.3 & 1 & 2.7 & 36 & 97.3 & 1 & 2.7 & 36 & 97.3 & 1 & 2.7 & 108 & 97.3 & 3 & 2.7 \\
\hline 7. The old dressing is removed. & 37 & 100.0 & - & - & 37 & 100.0 & - & - & 37 & 100.0 & - & - & 111 & 100.0 & - & - \\
\hline $\begin{array}{l}\text { 8. Entrance site, sutures, } \\
\text { and surrounding tissues are } \\
\text { evaluated. }\end{array}$ & 37 & 100.0 & - & - & 37 & 100.0 & - & - & 37 & 100.0 & - & - & 111 & 100.0 & - & - \\
\hline $\begin{array}{l}\text { 9. The integrity of the catheter } \\
\text { and its hub is evaluated. }\end{array}$ & 37 & 100.0 & - & - & 37 & 100.0 & - & - & 37 & 100.0 & - & - & 111 & 100.0 & - & - \\
\hline 10. Gloves are removed. & 20 & 54.0 & 17 & 46.0 & 17 & 46.0 & 20 & 54.0 & 18 & 48.7 & 19 & 51.3 & 55 & 49.5 & 56 & 50.5 \\
\hline 11. Hand hygiene is performed. & 7 & 18.9 & 30 & 81.1 & 5 & 13.5 & 32 & 86.5 & 6 & 16.2 & 31 & 83.8 & 18 & 16.2 & 93 & 83.8 \\
\hline 12. Sterile gloves are put on. & 11 & 29.7 & 26 & 70.3 & 11 & 29.7 & 26 & 70.3 & 11 & 29.7 & 26 & 70.3 & 33 & 29.7 & 78 & 70.3 \\
\hline $\begin{array}{l}\text { 13. The region is wiped with } \\
\text { outward circular movements } \\
\text { starting from the entrance site. }\end{array}$ & 37 & 100.0 & - & - & 37 & 100.0 & - & - & 37 & 100.0 & - & - & 111 & 100.0 & - & - \\
\hline $\begin{array}{l}\text { 14. The wiped region is allowed } \\
\text { to dry. }\end{array}$ & 28 & 75.7 & 9 & 24.3 & 26 & 70.3 & 11 & 29.7 & 26 & 70.3 & 11 & 29.7 & 80 & 72.1 & 31 & 27.9 \\
\hline $\begin{array}{l}\text { 15. The region is dressed with } \\
\text { sterile transparent or gauze } \\
\text { dressing, placing the dressing so } \\
\text { that the entrance site remains in } \\
\text { the center. }\end{array}$ & 37 & 100.0 & - & - & 37 & 100.0 & - & - & 37 & 100.0 & - & - & 111 & 100.0 & - & - \\
\hline $\begin{array}{l}\text { 16. The cap of the lumen is } \\
\text { removed. }\end{array}$ & 8 & 21.6 & 29 & 78.4 & 7 & 18.9 & 30 & 81.1 & 7 & 18.9 & 30 & 81.1 & 22 & 19.8 & 89 & 80.2 \\
\hline $\begin{array}{l}\text { 17. The catheter hub is cleaned } \\
\text { with chlorhexidine, povidone } \\
\text { iodine or alcoholic wipes. }\end{array}$ & 4 & 10.8 & 33 & 89.2 & 4 & 10.8 & 33 & 89.2 & 4 & 10.8 & 33 & 89.2 & 12 & 10.8 & 99 & 89.2 \\
\hline $\begin{array}{l}\text { 18. The syringe filled with } 0.9 \% \\
\text { saline solution is placed to the } \\
\text { hub and the clamp is opened. }\end{array}$ & 2 & 5.4 & 35 & 94.6 & 2 & 5.4 & 35 & 94.6 & 2 & 5.4 & 35 & 94.6 & 6 & 5.4 & 105 & 94.6 \\
\hline $\begin{array}{l}\text { 19. The syringe is withdrawn to } \\
\text { observe positive blood return. }\end{array}$ & - & - & 37 & 100.0 & - & - & 37 & 100.0 & - & - & 37 & 100.0 & - & - & 111 & 100.0 \\
\hline $\begin{array}{l}\text { 20. The hub is flushed with the } \\
\text { saline solution in the syringe. }\end{array}$ & 2 & 5.4 & 35 & 94.6 & 2 & 5.4 & 35 & 94.6 & 2 & 5.4 & 35 & 94.6 & 6 & 5.4 & 105 & 94.6 \\
\hline 21. A new cap is put on the hub. & 10 & 27.0 & 27 & 73.0 & 9 & 24.3 & 28 & 75.7 & 9 & 24.3 & 28 & 75.7 & 28 & 25.2 & 83 & 74.8 \\
\hline 22. Gloves are removed. & 37 & 100.0 & - & - & 33 & 89.2 & 4 & 10.8 & 34 & 91.9 & 3 & 8.1 & 104 & 93.7 & 7 & 6.3 \\
\hline 23. Hand hygiene is performed. & 17 & 46.0 & 20 & 54.0 & 14 & 37.8 & 23 & 62.2 & 14 & 37.8 & 23 & 62.2 & 45 & 40.5 & 66 & 59.5 \\
\hline $\begin{array}{l}\text { 24. The time and date of the } \\
\text { dressing change and the initials } \\
\text { of the nurse are written on the } \\
\text { dressing. }\end{array}$ & 37 & 100.0 & - & - & 37 & 100.0 & - & - & 37 & 100.0 & - & - & 111 & 100.0 & - & - \\
\hline $\begin{array}{l}\text { 25. The procedures and } \\
\text { observations are recorded on the } \\
\text { nurse's observation form. }\end{array}$ & 5 & 13.5 & 32 & 86.5 & 6 & 16.2 & 31 & 83.8 & 7 & 18.9 & 30 & 81.1 & 18 & 16.2 & 93 & 83.8 \\
\hline
\end{tabular}




\section{DISCUSSION}

In our study, we found that participants were mostly young nurses and had limited practical nursing experience. We believe that this may be because, in Turkey, newly graduated nurses are commonly appointed to ICUs to gain experience. Other similar studies have obtained comparable results, where the majority of nurses were in the age group of 26-30 and had 1-5 years of professional experience $[7,8,29]$.

Central venous catheterization care training is routinely given in ICUs in Turkey. The majority of the nurses stated that they had received in-service training on CVC care and that they found this training to be "adequate". Aydogdu and Akgun investigated the knowledge of nurses on CVC care and the influencing factors and found that the majority of nurses received "inservice training" for CVC care [30]. We believe that the nurse attendance rate at national and international congresses and conferences is low because hospitals generally do not provide sufficient financial support for nurses to participate in scientific activities.

We determined that the majority of nurses did not have available resources to refer to in the context of CVC care in their workplace and that they most commonly referred to the hospital information system. Whereas, the availability and accessibility of different resources in ICUs are very important to increase and maintain the quality of nursing care.

It is critical to perform hand hygiene after touching a potentially contaminated area and before putting on sterile gloves. All guidelines for CVC care likewise emphasize performing hand hygiene during catheter care [24,26,27,31]. In our study, almost all nurses started the process by performing hand hygiene in all three observations. However, in the following steps, the vast majority did not perform hand hygiene after removing their contaminated gloves or before putting on sterile gloves. In a similar study, Mutlu and Senturan, observed nurses before and after Hickman catheter care training and noted that nurses had shortcomings in performing hand hygiene before wearing sterile gloves in both observations [11]. The literature indicates that hand hygiene compliance rates are higher among nurses than among other health workers but still not at the expected level $[32,33]$. The reasons for this behavior were as follows: hand hygiene was perceived as less important than other procedures, nurses had insufficient time due to a heavy workload, sinks were inappropriately located and small, experienced health personnel set bad examples, and nurses had allergic reactions to hand antiseptics [32,33].

We observed that the majority of the nurses performed CVC care with disposable gloves without wearing sterile gloves. Basic nursing textbooks $[24,26]$ recommend using sterile gloves in CVC care, while CVC care guidelines $[25,27,28]$ state that this application can also be done with disposable gloves. In our study, the rate of sterile glove use was very low, and we found that this rate was significantly higher in the age group of $\geq 26$ years and among nurses with master's degree. These results are important as they demonstrate the importance of professional experience and education. Snarski et al., examined nursing practices that aimed to prevent CRBSI in hematopoietic stem cell transplant patients and found the rate of sterile glove use to be $82 \%$ [34]. Mutlu and Senturan found this rate to be $77.3 \%$ [11]. The results of these studies differ from our findings. We believe that the low rate of sterile glove use in our study stems from habit, availability, high cost and time considerations. The nurses found using disposable gloves and an antiseptic solution to be more practical.

In our study, we observed that all nurses wiped the catheter region with sterile gauze and antiseptic solution. The literature recommends using chlorhexidine gluconate (CHG) for catheterization sites and states that $10 \%$ povidone-iodine or $70 \%$ alcohol may also be used if CHG is contraindicated [25,27,28,31]. However, in our study, we did not observe any nurse using CHG for skin antisepsis; instead, they mostly used povidone-iodine. The reason for this might be the lower cost and accessibility.

Guidelines indicate that to achieve maximum anti-microbial effect in catheter dressings, the skin needs to be allowed to dry after the application of antiseptic solution [24-28,31]. In our study, we observed that a considerable number of nurses applied dressings without letting the antiseptic solution dry. Similar studies have reported variable results. Lai et al. [35] and Mutlu and Senturan [11] indicated that this rate was high among nurses. In contrast, Gerceker et al., stated that nurses did not perform this step prior to training [18]. Arslan et al., indicated that few nurses were observed to scrub the stopcock entrance with $70 \%$ alcohol and subsequently wait for it to dry [16]. Nurses need to be motivated to perform this step, it is simple but is significant in preventing infection.

Cleaning the catheter hub, a microorganism entrance site, is crucial for the prevention of CRBSIs. According to the Joint Commission International (JCI) and the Centers for Disease Control and Prevention (CDC), the catheter's hub should be rubbed with the appropriate antiseptic solution before any intervention. If the hub is not cleaned, organisms from the contaminated hub may migrate to the inner surface of the CVC [36,37]. Wright et al., evaluated the effect of catheter hub cleaning on the development of CRBSIs and concluded that hub cleaning significantly decreased the infection rate [38]. However, in our study, the catheter hub cleaning rates were very low. Other studies reported similar results $[16,39,40]$. In addition, we found that this rate was higher in nurses with more professional experience. This finding shows that clinical experience is an effective factor in skill improvement.

Guidelines recommended CVC lumens to be washed with at least $10 \mathrm{~mL}$ of sodium chloride solution before and after each use $[25,27]$. In contrast, in the present study, almost none of the nurses practiced flushing. Arslan et al., stated that flushing the CVC line was frequently performed incorrectly by the nurses in all three treatment hours [16]. Gerceker et al., also stated that nurses had shortcomings in this step of the procedure and that the concern of nurses in catching up with treatment needs was a contributing factor [18]. Other factors that may have contributed to our result are patients with continuing infusions, concerns over disrupting the current treatment, as it may affect 
the patient's vital findings, and believing that the procedure would be a waste of time.

We observed that the majority of nurses did not put a new cap on the lumen after cleaning the catheter hub, an application that has been shown to reduce the risk of infection. This shows that nurses have shortcomings in these practices. Nursing staff shortages, nurses' work overload, and inadequate supervision could contribute to such a low practice level. Additionally, it was determined that the recording the process on the nurse's observation form was not done by majority of the nurses. Keeping records ensures that the communication between nurses is understandable and healthy and it also constitutes a legal basis in a possible case.

\section{Limitations of the Study}

The researcher was able to observe the nurses only during day shifts of the week, as per the request of the nurses in charge of the ICUs. For this reason, nurses who often worked the night shift refused to participate in the study, stating that 3 observations were not feasible. Additionally, in several ICUs, the nurses refused to participate in the study, claiming that it would disrupt their routines and increase the workload of the day shift, as CVC care was mostly done during the night shift, together with patient care. These factors reduced the number of nurses included in the study and affected the participation rate.

Prior to initiation of this observational study, nurses were informed about the ethical principles. The nurses were aware of the fact that being a participant in an observational study, might affect their skills negatively while performing CVC care. In addition, this study was conducted with ICU nurses of three hospitals only, and hence, the results might not be generalized to all nurses working in ICUs in Turkey.

\section{Conclusion}

This study showed that nurses had inadequate skills of CVC care applications. According to the results of this study that majority (93.7\%) of the nurses had performed the hand hygiene before starting the CVC care procedure but seldom performed hand hygiene after the procedure. The majority of the nurses $(70.3 \%)$ did not use sterile gloves during the CVC care applications; they almost never flushed and maintained the catheter hub, and they did not adequately keep records after the CVC care procedure. In line with these results, we recommend that nurses' CVC care skills must be enriched with professional theoretical and practical trainings; preparing the CVC care procedure based on evidence-based practices and ensuring that nurses have easy access to these documents. Further studies with larger samples are needed to confirm our results.

\section{Acknowledgements}

We would like to thank the participants for their support and contribution.

\section{Ethics Committee Approval}

The study was approved by the Ethics Committee of Ankara Yildirim Beyazit University, Ankara, Turkey (Date: 21/11/2018, Number: 102). Written informed concent was obtained from each participant.

Funding: The authors declare that this study received no financial support.

Conflict of interest: The authors declare no conflicts of interest.

Author Contibutions: G.K., E.E.K. Concept. G.K., E.E.K. Design. G.K. Data Collection or Processing. G.K., E.E.K. Analysis, Interpretation. G.K., E.E.K. Literature Search. G.K., E.E.K. Writing. Both authors approved the final version of the article.

\section{REFERENCES}

[1] Kurt B. Evidence-based nursing practices to prevent central venous catheter infections. Journal of Adnan Menderes University Health Sciences Faculty 2018;2:21-7.

[2] Hakyemez IN, Yildirmak MT, Cetmeli G, Iris NE. Prevalence, causative microorganisms, and risk factors of central venous catheter-related infections in a tertiary care hospital. Abant Med J 2016;5:108-17.

[3] Wright MO, Decker SG, Allen-Bridson K, Hebden JN, Leaptrot D. Healthcare-associated infections studies project: An American Journal of Infection Control and National Healtcare Safety Network data quality collaboration: Location mapping. Am J Infect Control 2018;46:577-8. https://doi. org/10.1016/j.ajic.2017.12.012.

[4] Karasu D, Yilmaz C, Durmus G, Ozer D, Caglayan U, Karaduman I, Asan A. Evaluation of healthcare-associated infections in critically ill patients receiving long-term treatment in the intensive care unit. Klimik Journal 2016; 29:71-6. doi:10.5152/kd.2016.17

[5] Zabidi HAZ, Ali GM, Naqshbandi E. The effect of nurses' implementation of central vascular catheter maintenance care bundle on bloodstream infection among ICU patients in $\mathrm{KFGH}$ and KAAUH. International Journal of Nursing Didactics 2018; 7:10-6. doi: 10.15520/ijnd.v7i12.2153

[6] Sanli D, Sarikaya A. Evidenced-based nursing care management at central venous catheters. Journal of the Turkish Society of Critical Care Nurses 2016;20:84-97.

[7] Alkubati SA, Ahmed NT, Mohamed ONE, Fayed AM, Asfour HI. Health care workers' knowledge and practices regarding the prevention of central venous catheter-related infection. Am J Infect Control 2015;43:26-30. doi:10.1016/j.ajic.2014.09.021

[8] Bati B, Ozyurek P. Knowledge levels of intensive care unit nurses on central venous catheters. Journal of Medical and Surgical Intensive Care 2015;6:34-8. doi: 10.5152/ dcbybd.2015.828

[9] Gnanarani J, Venkatesan L, Manikandan. Effectiveness of central line bundle care upon the knowledge and compliance staff nurses in the ICU. International Journal of Advance Research, Ideas and Innovations in Technology 
2018;4:2059-63. https://www.ijariit.com/manuscripts/v4i3/ V4I3-1793.pdf Accessed: June 25, 2019

[10] Manzo BF, Mariano DR, Ferreira FMC, et al. Knowledge and behavior of professionals about bundled strategies of central venous catheter. Rev Bras Enferm 2019;72:50-6. doi: 10.1590/0034-7167-2018-0164.

[11] Mutlu EY, Senturan L. Effects of hickman catheter care training on practices of nurses. International Journal of Caring Sciences 2017; $10: 16-33$.

[12] Ozen N, Kose T, Terzioglu F. Evidence-based practices in the prevention of central venous catheter infections: Knowledge of intensive care nurses. Turk J Intensive Care 2020;18:91-8. doi: 10.4274/tybd.galenos.2019.25991

[13] Sharour A. Oncology nurses' knowledge about central line catheter: caring, complications, and applications among cancer patients - a cross-sectional study. J Vasc Nurs 2018;36:145-8. doi:10.1016/j.jvn.2018.04.002.

[14] Gillespie BM, Polit DF, Hamlin L, Chaboyer W. Developing a model of competence in the OR: Psychometric validation of perceived perioperative competence scale-revised. Int J Nurs Stud 2012;49:90-101. doi:10.1016/j.ijnurstu.2011.08.001.

[15] Infection prevention and control of healthcare-associated infections in primary and community care. National Institute for Health and Care Excellence 2012. https://www.nice.org.uk/ guidance/cg139/resources/healthcareassociated-infectionsprevention-and-control-in-primary-and-community-carepdf-351.095.18767045 Accessed:July 11, 2019

[16] Arslan GG, Ozden D, Alan N, Yilmaz I, Ayik C, Goktuna G. Examination of nursing drug administration practices via central venous catheter: An observational study. J Vasc Access 2020;21:426-33. doi: 10.1177/112.972.9819880979.

[17] Devi R, Ghai S, Singh NV, Puri GD. A methodological study to develop a standard operational protocol for nurses on central line catheter care of patients in selected intensive care units. Indian J Crit Care Med 2017;21:483-7. doi: 10.4103/ijccm. IJCCM_261_16.

[18] Gerceker G, Yardimci F, Aydinok Y. Randomized controlled trial of care bundles with chlorhexidine dressing and advanced dressing to prevent catheter related bloodstream infections in pediatric hematology-oncology patients. Eur J Oncol Nurs 2017;28:14-20. doi:10.1016/j.ejon.2017.02.008.

[19] Marschall J, Mermel LA, Fakih M, et al. Strategies to prevent central line-associated bloodstream infections in acute care hospitals. Infect Control Hosp Epidemiol 2014;35:753-71. doi:10.1086/676533.

[20] Global Infection Prevention and Control Unit. Evidence of hand hygiene as the building block for infection prevention and control. World Health Organization 2017. https:// creativecommons.org/licenses/by-nc-sa/ 3.0/igo. Accessed: August 4, 2019

[21] Caner N, Tekinsoy KP. The assessment of the intramuscular and intravenous drug administration steps of nurses: Observation study. HUHEMFAD-JOHUFON 2019;6:177-85. doi: 10.31125/hunhemsire.630812.
[22] Kazan EE, Gorgulu S. Skills of the nurses about the administration of subcutaneous low molecular weight heparin injection. HUHEMFAD-JOHUFON 2009:1-13.

[23] Acun A, Caliskan N. Evaluation of effectiveness of central venous catheter related bloodstream infections in the antesty and reanimation intensive care units of the bundle. Ann Med Res 2021;28:792-8. doi: 10.5455/annalsmedres.2020.06.587.

[24] Berman A, Snyder SJ. Kozier\& Erb's fundamentals of nursing, concepts, process and practice. 10th ed. Pearson, 2015: 814-27.

[25] Iseri A, Cinar B, Duzkaya DS, , et al. National vessel access management guide. Turkish Journal of Hospital Infections 2019;23:1-54. http://www.hider.org.tr/global/Dernek_ Kilavuzlari/HID_Damar\%20Erisimi\%20Rehberi_2019.pdf . Accessed: August 16, 2019

[26] Lynn P B. Taylor's clinical nursing skills. A nursing process approach. 5th ed. Philadelphia, PA:Wolters Kluwer, 2018: 81321.

[27] O'Grady NP, Alexander M, Burns LA, et al. Guidelines for the prevention of intravascular catheter-related infections. Clin Infect Dis 2011;52:162-93. doi:10.1093/cid/cir257.

[28] Sardan YC, Guner R, Cakar N, et al. Guidelines for the prevention of intravenous catheter infections. Turkish Journal of Hospital Infections 2013;17:233-78.http://www. hider.org.tr/global/Dernek_Kilavuzlari/Damar_ici_Kateter_ infeksiyonlarinin_Onlenmesi_Kilavuzu.pdf. Accessed: July 25,2019

[29] Esposito MR, Guillari A, Angelillo IT. Knowledge, attitudes, and practice on the prevention of central line-associated bloodstream infections among nurses in oncological care: A cross-sectional study in an area of Southern Italy. PloS One 2017;12:1-11. doi:10.1371/journal.pone. 0180473.

[30] Aydogdu S, Akgun M. Determination of knowledge levels of nurses and the factors affecting the level of knowledge in central venous catheter care. Clinical Nursing Studies 2020;8:1-9. https://doi.org/10.5430/cns.v8n2p1.

[31] Preventing central line-associated bloodstream infections: A global challenge, a global perspective. The Joint Commission 2012. https://www.jointcommission.org/-/ media/deprecated-unorganized/imported-assets/tjc/ system-folders/topics-library/clabsi_monographpdf. pdf? db=web\&hash=86103821F3C7FF8A7683C933EA0CB391 Accessed: March 7, 2019

[32] Abdo NM, Fadhli MA. Improving hand hygiene compliance among healthcare workers in intensive care unit: an interventional study. Int J Community Med Public Health 2018;5:3747-52.http://dx.doi.org/10.18203/2394-6040. ijcmph20183558.

[33] Yurttas A, Kaya A, Engin R. Examination of hospital infection and hand hygiene compliance in intensive care unit of a university hospital. Arch Health Sci Res 2017;4 :1-7. doi:10.17681/hsp.115490.

[34] Snarski E, Mank A, Iacobelli S, et al. Current practices used for the prevention of central venous catheter-associated infection in hematopoietic stem cell transplantation recipients: A survey from the infectious diseases working party and nurses' 
group of EBMT. Transpl Infect Dis 2015;17:558-65. https:// doi.org/10.1111/tid.12399.

[35] Lai NM, Lai AN, O'Riordan E, et al. Skin antisepsis for reducing central venous catheter-related infections. Cochrane Database of Syst Rev 2016;7: CD010140. doi: 10.1002/14651858. CD010140.pub2.

[36] Central venous catheter hub cleaning prior to accessing. Centers for Disease Control and Prevention 2011. https:// www.cdc.gov/dialysis/PDFs/collaborative/Protocol-HubCleaning-FINAL-3-12.pdf. Accessed: August 20, 2019

[37] Preventing central line-associated bloodstream infections: Useful tools, an international perspective, scrub the hub. The Joint Commission 2013. https://www.jointcommission.org/-/ media/tjc/documents/resources/health-services-research/ clabsi-toolkit/clabsi_toolkit_tool_3-21_scrub_the_hubpdf.
pdf?db=web\&hash=79BF0D29BD4AAF13DEC3C3DE5AB90494. Accessed: August 20, 2019

[38] Wright MO, Tropp J, Schora DM, Grant MD, Peterson K. Continuous passive disinfection of catheter hubs prevents contamination and bloodstream infection. Am J Infect Control 2013;41:33-8. doi:10.1016/j.ajic.2012.05.030.

[39] Desra AP, Breen J, Harper S, Slavin MA, Worth LJ. Aseptic technique for accessing central venous catheters: Applying a standardized tool to audit 'scrub the hub' practices. J Vasc Access 2016;17:269-72. doi:10.5301/jva.5000509.

[40] Hosaf S. Investigation of the effectiveness of continuous education given with internet-mediated communication to nurses on central venous catheter care management (thesis). Izmir: Ege Univ; 2019. 